\title{
Thermodymanic Considerations on Gold Dissolution in Different Lixiviants (I)
}

\author{
CATALIN ALEXANDRU BARBU, ION CONSTANTIN, MIHNEA COSMIN COSTOIU, MIHAI BUZATU, AUGUSTIN SEMENESCU* \\ University Politehnica of Bucharest, 313 Splaiul Independentei, 060021, Bucharest, Romania
}

\begin{abstract}
The paper presents the main thermodynamic aspects related to gold dissolution in different lixiviants. We analyzedthe thermodynamic stability of the gold complexes with the most representative lixiviants with potential for use in the gold industry. Based on the stability constants we determined the electrode potentials of the gold dissolution reactions in variouslixiviants and we presented the electrochemical mechanism of gold dissolution is alkaline cyanide solutions.
\end{abstract}

Keywords:gold, constantsof thermodynamic stability, electrodepotential, lixiviants

Cyanidation has been used for over 130 years worldwide in the gold industry, being considered the most efficient method of processing a wide range of auriferous raw materials.Given the downside of cyanide use, especially related to its toxicity, there has always been a real interest in finding alternatives to leaching auriferous ores under safer health conditions and environmental protection.

Concerns in this regard have intensified especially over the past 25 years, coupled with increased environmental protection requirements, in particular related to the drastic reduction of the accepted emissions levels of substances considered dangerous for being discharged into the environment and / or storage of technological byproducts considered toxic to flora, fauna and humans. Such measures have been imposed especially in the countries of the European Union, but also in other developed countries. For example, atthe level of the European Union, even if the proposal to ban all cyanide uses has been rejected, stringent cyanide waste limits have been set by European Parliament Directive 2016/21 / EC in 2006, with particular reference to tailings ponds of cyanidation residues [1]. As a result, including in Romania, several new projects have been blocked during the licensing phase, which involved the exploitation of auriferous deposits by using cyanides, such as the Rosia Montana and Certej [2,3]. Under these circumstances, one can easily understand the interest that the important gold industry producers show in the development of viable alternatives for auriferous ore leaching, so as to replace the current cyanide-based technologies. In this paper we intend to perform a thermodynamic analysis of the potential lixiviants capable of replacing cyanides in the auriferous ore leaching process.

\section{General considerations on lixiviants alternative to cyanides}

In general, the quality of a lixiviantis appreciated on the basis of several technological, ecological and economic criteria. The technological criteria mainly address the following aspects:

- the thermodynamic stability and the ability of the lixiviant to dissolve noble metals with the formation of stable complexes which should not decompose during leaching or subsequent operations of phase separation or of extraction from solutions;
- the selectivity of the lixiviant so as to limit its side reactions with other ore constituents, with direct effects on the lixiviant consumption and the purity of the resulting solutions;

- the corrosive capacity of the lixiviant related to the equipment involved in the process;

- the diversity of the raw materials, i.e. the types of auriferou sores that can be leached with appropriate extraction yields;

- the necessary technological parameters, in particular the differences in the $\mathrm{pH}$ and electrode potentials values at which the lixiviant is effective, the temperature, pressure, density of the pulp, the need for auxiliary materials $(\mathrm{pH}$ modifiers, catalytic oxidants, stabilizers, anti-activators, etc.);

- the lixiviant consumption and the possibilities of its regeneration and recirculation in the process.

The ecological criteria address the toxicity of the lixiviant to humans and the environment, the emissions that can occur during leaching, the possibilities of detoxification of technological by-products and their sustainable storage, e.g. the safety of tailings ponds.

The economic criteria, which are decisive in most cases, are the capital and operating costs, the expenses weighting regarding the cost of the lixiviant and of the auxiliary materials, the detoxification costs and the longterm management of tailings ponds etc..

\section{Thermodynamic stability of gold complexes with different lixiviants}

From the the rmodynamic view point, one of the main conditions to be met by a lixiviant is its stability and that of the complex that it forms with gold, which should ensure the prevention of hydrolysis, precipitation or disproportioning reactions both during the leaching process, and in its later phases. Depending on the nature of the lixiviant, it can form complexes with both the monovalent and trivalent gold, and their thermodynamic stability is appreciated by the value of the normal free energy variation of the formation reaction of the auriferous complexes from the gold and ligand cations or by the value of the stability constant equivalent to the balance constant of this reaction, respectively: 


$$
\begin{aligned}
& A u^{z+}+n L^{y-}=A u L_{n}^{z-n y} \\
& \Delta G^{0}=-R T \ln \beta_{n} \\
& \beta_{n}=\frac{\left[A u L_{n}^{z-n y}\right]}{\left[A u^{z+}\right] \cdot\left[L^{-y}\right]^{n}}=\frac{\left[A u L_{n}^{z-n y}\right]}{K_{S}}
\end{aligned}
$$

where:

$z$ is the gold valency $(1$ or 3$)$;

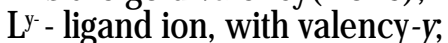

$\mathrm{n}$ - the number of ligands bound to the gold cations, called coordination number ( $n=2$ for the monovalent gold and $n=4$ for the trivalent gold);

AuL ${ }^{\text {z-my }}$ - theauriferous complex;

$\Delta \mathrm{G}^{\mathrm{n}}$ - the variation of the normal free energy of the auriferous complex formation;

$\mathrm{R}$ - the general gas constant $(8.314 \mathrm{~J} / \mathrm{mol}, \mathrm{K})$;

$\mathrm{T}$ - the absolute temperature $(\mathrm{K})$;

$\beta_{n}$ - thestability constant, $\beta_{2}$ for the monovalent gold, $\beta_{4}$ for the trivalent gold;

[i] - the thermodynamic activity or the concentration of the species in brackets;

$\mathrm{K}_{\mathrm{c}}$ - the solubility product.

The higher the stability constant, respectively, the lower solubility product, the higher the probability of formation and the thermodynamic stability of the auriferous complex. Due to the large complexities of systems involving gold complexes with different ligands, there are differences, sometimes significant, between the values of the stability constants determined by different researchers. The values of the formation standard free energy variations and of the stability constants for the auriferous complexes formed with the main ligands are shown in Table 1.

From the values of the stability constants it is obvious that from the strict view point of the gold complexes stability, the best lixiviants are in descending order cyanide, disulfide, thiosulfate, thiourea, ammonia, iodine, thiocyanate, bromine and chlorine for the monovalent gold respectively ammonia, cyanide, iodine, thiocyanate, bromine and chlorine for the trivalent gold.

Also, from the data presented in table 1, a higher stability of the trivalent gold complexes is observed and the fact that, according to the nature of the ligand, the highest stability is found in the complexes formed in the cyanide solutions and the lowest in the complexes formed in the chloride medium. However, the stability of the auriferous complexes also depends on the nature of the donor ligand atoms, i.e., the ligand atoms directly bonded to the gold ions. The stability of the complexes decreases with the increase in the electronegativity of the donor ligand atoms, because the tendency of the atom to attract electrons increases.In general, it can be argued that the more electronegative donor atoms prefer the higher valency gold ion, that is, $\mathrm{Au}^{3+}$, while the less electronegative donor atom ligands prefer the lower valency, auriferous ions i.e. $\mathrm{Au}^{+}$.Therefore, monovalent gold forms more stable complexes with weaklier electronegative donors, such as $\mathrm{S}, \mathrm{C}$, Se and $\mathrm{P}$, while trivalent gold forms more stable complexes with ligands whose donor atoms are more electronegative such asN $\mathrm{O}, \mathrm{F}, \mathrm{Cl}$ etc. [6]. This means that in the presence of a stronger ligand, trivalent gold may be

\begin{tabular}{|c|c|c|c|c|}
\hline \multicolumn{2}{|c|}{ Ligand } & \multirow[b]{2}{*}{ Complex } & \multirow{2}{*}{$\begin{array}{c}\Delta G_{298}^{0} \\
\mathrm{~J} / \mathrm{mol}\end{array}$} & \multirow[b]{2}{*}{$\lg \beta_{2}$} \\
\hline Name & Formula & & & \\
\hline \multicolumn{5}{|c|}{ The monovalent gold complexes } \\
\hline cyanide & $\mathrm{CN}^{-}$ & $A u(C N)_{2}^{\overline{-}}$ & -218495 & 38.3 \\
\hline sulfur & $s^{2-}$ & $A u S^{-}$ & -207085 & 36.3 \\
\hline disulfide & $\mathrm{HS}^{-}$ & $A u(H S)_{2}$ & $\begin{array}{l}-187118 \\
-170574^{*}\end{array}$ & $\begin{array}{l}32.8^{\circ} \\
29.9^{\circ}\end{array}$ \\
\hline sulphite & $\mathrm{SO}_{3}^{2-}$ & $\mathrm{Au}\left(\mathrm{SO}_{3}\right)_{2}^{3-}$ & $\begin{array}{l}-152889 \\
-85572^{*}\end{array}$ & $\begin{array}{c}26.8 \\
15^{*}\end{array}$ \\
\hline thiosulfate & $\mathrm{S}_{2} \mathrm{O}_{3}^{2-}$ & $\mathrm{Au}\left(\mathrm{S}_{2} \mathrm{O}_{3}\right)_{2}^{3-}$ & $\begin{array}{l}-148325 \\
-163728^{\circ}\end{array}$ & $\begin{array}{l}26.0 \\
28.7^{\circ}\end{array}$ \\
\hline thiourea & $\mathrm{CS}\left(\mathrm{NH}_{2}\right)_{2}$ & $\mathrm{Au}\left(\mathrm{CS}\left(\mathrm{NH}_{2}\right)_{2}\right)_{2}^{+}$ & $\begin{array}{l}-125506 \\
-132922^{*}\end{array}$ & $\begin{array}{l}22.0^{\circ} \\
23.3^{\circ}\end{array}$ \\
\hline ammonia & $\mathrm{NH}_{3}$ & $\mathrm{Au}\left(\mathrm{NH}_{3}\right)_{2}^{+}$ & $\begin{array}{l}-108392 \\
-151178^{\circ}\end{array}$ & $\begin{array}{l}19.0 \\
26.5^{\circ}\end{array}$ \\
\hline iodine & $I^{-}$ & $\mathrm{AuI}_{2}^{-}$ & $\begin{array}{l}-108392 \\
-106110^{*}\end{array}$ & $\begin{array}{l}19.0 \\
18.6^{*} \\
\end{array}$ \\
\hline thiocyanate & $\mathrm{SCN}^{-}$ & $\mathrm{Au}(\mathrm{SCN})_{2}^{-}$ & -97552 & 17.1 \\
\hline bromine & $\mathrm{Br}^{-}$ & $\mathrm{AuBr}_{2}^{-}$ & -68458 & 12.0 \\
\hline chlorine & $\mathrm{Cl}^{-}$ & $\mathrm{AuCl}_{2}^{-}$ & -51343 & 9.0 \\
\hline \multicolumn{4}{|c|}{ The trivalent gold complexes } & $\lg \beta_{4}$ \\
\hline cyanide & $\mathrm{CN}^{-}$ & $\mathrm{Au}(\mathrm{CN})_{4}^{-}$ & -319470 & 56.0 \\
\hline ammonia & $\mathrm{NH}_{3}$ & $\mathrm{Au}\left(\mathrm{NH}_{3}\right)_{4}^{3+}$ & -336584 & 59.0 \\
\hline iodine & $I^{-}$ & $\mathrm{AuI}_{4}^{-}$ & -272120 & 47.7 \\
\hline thiocyanate & $\mathrm{SCN}^{-}$ & $\mathrm{Au}(\mathrm{SCN})_{4}^{-}$ & $\begin{array}{l}-239602 \\
-250442^{*}\end{array}$ & $\begin{array}{l}42.0 \\
43,9^{\circ}\end{array}$ \\
\hline bromine & $\mathrm{Br}^{-}$ & $\mathrm{AuBr}_{4}^{-}$ & -187118 & 32.8 \\
\hline chlorine & $\mathrm{Cl}^{-}$ & $\mathrm{AuCl}_{4}^{-}$ & $\begin{array}{l}-148325 \\
-144332^{\circ} \\
\end{array}$ & $\begin{array}{l}26.0 \\
25.3^{*}\end{array}$ \\
\hline
\end{tabular}
reduced to monovalent gold, thus producing the disproportioning of the trivalent gold to atomic gold. For
Table 1

VARIATIONS OF THE FORMATION STANDARD FREE ENERGY AND VALUES OF STABILITY CONSTANTS OF GOLD COMPLEXES WITH DIFFERENT LIGANDS [4, 5] 
example, monovalent gold preferentially forms complexes with ligands such as cyanide, thiourea, thiocyanates and thiosulphates (which contain weaker donor atoms), while trivalent gold preferentially forms complexes with ligands containing stronger donor atoms, such as, for example, the halogens.

\section{Electrode potentials of the electrochemical reactions for gold dissolution}

The general dissolution reaction of gold with various lixiviants with the formation of soluble auriferous complexes is of the type:

$$
A u+n L^{y-}=A u L_{n}^{z-n v}+z e
$$

This can be obtained reaction (1) with the oxidation reaction of the gold with the formation of monovalent or trivalent ions, respectively:

$$
\begin{gathered}
A u^{z+}+n L^{y-}=A u L_{n}^{z-n y} ; \quad E_{1}^{0} \\
\frac{A u=A u^{z+}+z e ;}{A u+n L^{y-}=A u L_{n}^{z-n y}+z e ; \quad E_{6}^{0}=E_{1}^{0}+E_{5}^{0}}
\end{gathered}
$$

where: $\mathrm{E}_{1}{ }^{0}, \mathrm{E}_{5}{ }^{0}, \mathrm{E}_{6}{ }^{0}$ are the standard electrode potentials of the respective reactions, in $\mathrm{V}$.

The electrode potential of reaction (1) is obtained according to the stability constant values, thus:

$$
\Delta G^{0}=-R T \ln \beta_{n}=-z E_{1}^{0} F
$$

\begin{tabular}{|c|c|c|c|}
\hline Ligand & Oxidation reaction & $\mathrm{E}^{0}, \hat{\mathrm{in}} \mathrm{V}$ & $\mathrm{pH}$ \\
\hline \multicolumn{4}{|c|}{ Oxidation of monovalent gold } \\
\hline & $A u=A u^{+}+e$ & $-1,69$ & \\
\hline cyanide & $A u+2 C N^{-}=A u(C N)_{2}^{-}+e$ & 0.5735 & $>9$ \\
\hline sulfur & $A u+S^{2-}=A u S^{-}+e$ & 0.4553 & $6-9$ \\
\hline disulfide & $A u+2 H S^{-}=A u(H S)_{2}^{-}+e$ & 0.2485 & $<9$ \\
\hline sulphite & $\mathrm{Au}+2 \mathrm{SO}_{3}^{2-}=\mathrm{Au}\left(\mathrm{SO}_{3}\right)_{2}^{3-}+e$ & -0.1061 & $>4$ \\
\hline thiosulfate & $\mathrm{Au}+2 \mathrm{~S}_{2} \mathrm{O}_{3}^{2-}=\mathrm{Au}\left(\mathrm{S}_{2} \mathrm{O}_{3}\right)_{2}^{3-}+e$ & -0.1534 & $8-10$ \\
\hline thiourea & $\mathrm{Au}+2 \mathrm{CS}\left(\mathrm{NH}_{2}\right)_{2}=\mathrm{Au}\left(\mathrm{CS}\left(\mathrm{NH}_{2}\right)_{2}\right)_{2}^{+}+e$ & -0.3898 & $<3$ \\
\hline ammonia & $\mathrm{Au}+2 \mathrm{NH}_{3}=\left(\mathrm{Au}\left(\mathrm{NH}_{3}\right)_{2}^{+}+e\right.$ & -0.5671 & $>9$ \\
\hline iodine & $A u+2 I^{-}=A u I_{2}^{-}+e$ & -0.5671 & $5-8$ \\
\hline thiocyanate & $A u+2 S C N^{-}=A u(S C N)_{2}^{-}+e$ & -0.6794 & $<3$ \\
\hline bromine & $\mathrm{Au}+2 \mathrm{Br}^{-}=\mathrm{AuBr}_{2}^{-}+e$ & -0.9808 & $5-8$ \\
\hline chlorine & $\mathrm{Au}+2 \mathrm{Cl}^{-}=\mathrm{AuCl}_{2}^{-}+e$ & -1.1581 & $<3$ \\
\hline \multicolumn{4}{|c|}{ Oxidation oftrivalent gold } \\
\hline & $A u=A u^{3+}+3 e$ & -1.50 & \\
\hline cyanide & $A u+4 C N^{-}=A u(C N)_{4}^{-}+3 e$ & -0.3968 & $>9$ \\
\hline ammonia & $\mathrm{Au}+4 \mathrm{NH}_{3}=\mathrm{Au}\left(\mathrm{NH}_{3}\right)_{4}^{3+}+3 e$ & -0.3377 & $>9$ \\
\hline iodine & $A u+4 I^{-}=A u I_{4}^{-}+3 e$ & -0.5603 & $5-8$ \\
\hline thiocyanate & $A u+4 S C N^{-}=A u(S C N)_{4}^{-}+3 e$ & -0.6726 & $<3$ \\
\hline bromine & $\mathrm{Au}+4 \mathrm{Br}^{-}=\mathrm{AuBr}_{4}^{-}+3 e$ & -0.8538 & $5-8$ \\
\hline chlorine & $\mathrm{Au}+4 \mathrm{Cl}^{-}=\mathrm{AuCl}_{4}^{-}+3 e$ & -0.9878 & $<3$ \\
\hline
\end{tabular}

respectively:

$$
E_{1}^{0}=\frac{R T \ln \beta_{n}}{z F}
$$

where: $\mathrm{F}$ - is the Faraday constant (96487C).
Under standard conditions, the electrode potentials of reaction (1) corresponding to the formation of the monovalent and trivalent gold complexes and those of the gold oxidation become:

$$
\begin{aligned}
&\left(E_{1}^{0}\right)_{A u^{+}}=0.0591 \lg \beta_{2} ; \quad\left(E_{1}^{0}\right)_{A u^{3+}}=0.0591 \frac{1 \lg \beta_{4}}{3} \\
&\left(E_{1}^{0}\right)_{A u^{+}}=0.0591 \lg \beta_{2}-1.69 \\
&\left(E_{1}^{0}\right)_{A u^{3+}}=0.059 \frac{1 \mathrm{~g} \beta_{4}}{3}-1.50
\end{aligned}
$$

Based on equations (10) and (11), the electrode standard potentials of the oxidation reactions of gold with different lixiviants were determined and given in Table 2. According to the second principle of thermodynamics, the gold dissolving reactions with different lixiviants under standard conditions are produced if they present positive values of the oxidation potential. From the data presented in table 2 it appears that under standard conditions gold can only be dissolved as monovalent gold in the presence of cyanide, sulfur and disulfide ions, while all the other lixiviants require the presence in the solution of an oxidant capable of taking overthe electrons released from the electrochemical oxidation reactions of gold. The traditional oxidant used in leaching processes is oxygen in various forms, air, air enriched in oxygen or technical oxygen. However, in some cases,the oxidative capacity of oxygen is insufficient to ensure that the gold dissolution reactions are produced at acceptable rates, thus requiring stronger oxidants such as perhydrol, ozone, divalent copper ions, trivalent iron ions or various halogens (table 3 ).
Table 2

ELECTRODE STANDARD

POTENTIALS OF GOLD DISSOLUTION REACTIONS AND THE pH REQUIRED 


\begin{tabular}{|c|c|c|c|}
\hline Lixiviant & Oxidant & Catalyst & Stabilizer \\
\hline cyanide & $\mathrm{O}_{2}$ (air) & - & - \\
\hline thiosulfate & $\mathrm{O}_{2}$ (air) & $\begin{array}{l}\mathrm{Cu}^{2+} \\
\mathrm{Ni}^{2+}\end{array}$ & Ammonia \\
\hline thiourea & $\begin{array}{c}\mathrm{Fe}^{3+} \\
\mathrm{H}_{2} \mathrm{O}_{2} \\
\mathrm{O}_{3}\end{array}$ & - & $\begin{array}{c}\mathrm{SO}_{2} \\
\text { Sodium metabisulfite }\left(\mathrm{Na}_{2} \mathrm{~S}_{2} \mathrm{O}_{5}\right)\end{array}$ \\
\hline thiocyanate & $\mathrm{Fe}^{3+}$ & - & - \\
\hline Ammonia & $\begin{array}{c}\mathrm{O}_{2} \\
\mathrm{H}_{2} \mathrm{O}_{2} \\
\mathrm{OCl}^{-} \text {(hypochlorite) } \\
\mathrm{Br}_{\mathrm{I}^{-}} \\
\mathrm{Cu}^{2+} \\
\end{array}$ & - & - \\
\hline Chlorine & $\begin{array}{c}\mathrm{Cl}_{2} \\
\mathrm{HOCl} \text { (hypochlorous } \\
\text { acid) }\end{array}$ & - & - \\
\hline
\end{tabular}

Table 3

COMPLEMENTARY REAGENTS FOR GOLD DISSOLUTION IN VARIOUS LIXIVIANTS
Due to the wide range of values in which the stability constants of the auriferous complexes vary, the standard oxidation potentials of the different ligand species vary by up to $2 \mathrm{~V}$. Consequently, in the leaching process, irrespective of the lixiviant used, there will be a competition between the gold dissolution reactions and the ligand oxidation reactions.This competition, if not entirely in favor of the gold dissolution, will lead to increased ligand consumption as aneffect of its oxidation.Also, in the case of low-rate gold dissolving lixiviants, certain catalysts or stabilizers are required, for instance, when using of thiosulfate and thiocyanate. Under these conditions, the ligand oxidation phenomenon may intensify, which further increases the reagents consumption. As a result, limiting the ligand oxidation reactions requires a leaching process in a reduced range of oxidation potential values for efficient gold dissolution.

Figure 1 shows the $\mathrm{pH}$ value ranges and the normal electrode reduction potentials at which the main lixiviants effectively dissolve gold. It is worth noting the wide range of the $\mathrm{pH}$ values and the electrode potential in the case of cyanide, compared to the other lixiviants capable of dissolving gold. At the same time, it should be noted that, for the lixiviants characterized by high oxidation potentials, for instance, in the case of halogens, both the secondary oxidation reactions of the sulphurous minerals in the ore, and of the respective ligand, intensify, which results in increased ligand consumption.

\section{Gold dissolution in alkaline cyanide solutions}

Several theories have been developed over time so as to be able to explain the mechanism of dissolving metallic gold in aqueous solutions of alkali metals cyanides[ 7-9]:

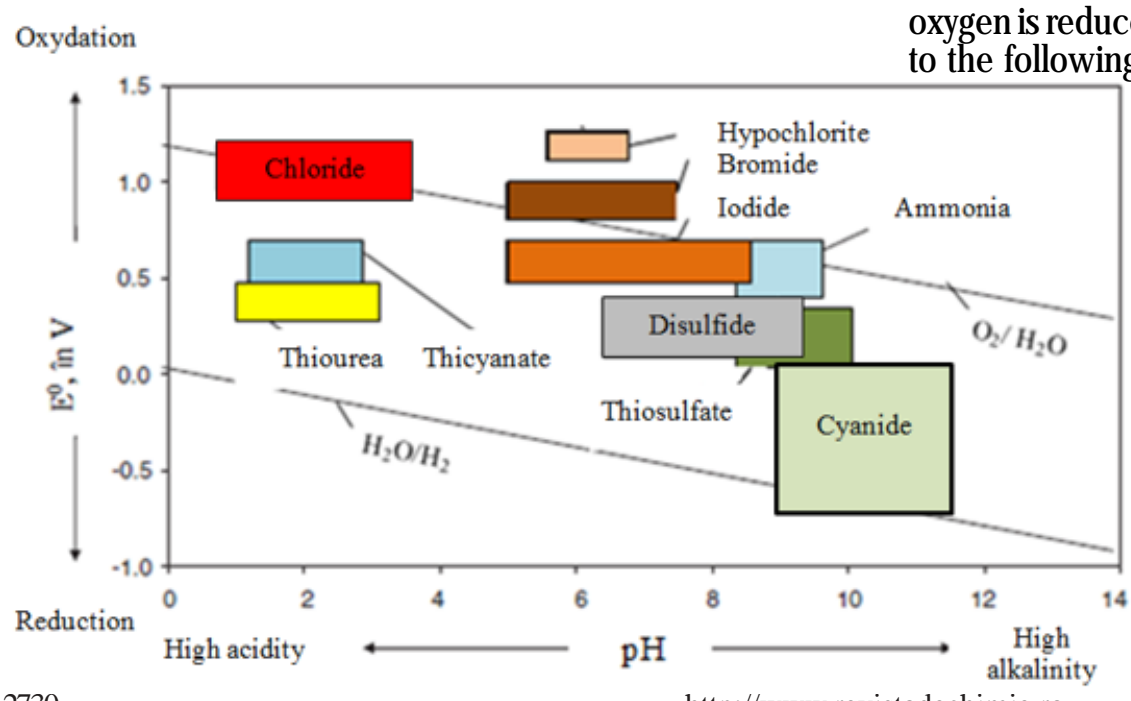

a. The Oxygen Theory: Elsner was the first to refer in 1846 to the positive role of oxygen in the gold dissolution of in the aqueous solutions of alkali metals cyanides according to the reaction:

$$
\begin{gathered}
4 \mathrm{Au}+8 \mathrm{MeCN}+\mathrm{O}_{2}+2 \mathrm{H}_{2} \mathrm{O} \rightarrow 4 \mathrm{MeAu}(\mathrm{CN})_{2}+4 \mathrm{MeOH} \\
\text { where } \mathrm{Me}=\{\mathrm{Na} \text { sau } \mathrm{K}\}
\end{gathered}
$$

b. The Theory of Hydrogen: L. Janin (1888) presented a gold dissolution reaction with the release of hydrogen, respectively:

$$
2 \mathrm{Au}+4 \mathrm{MeCN}+2 \mathrm{H}_{2} \mathrm{O} \rightarrow 2 \mathrm{MeAu}(\mathrm{CN})_{2}+2 \mathrm{MeOH}+\mathrm{H}_{2}
$$

c. The Theory of Perhydrol: G. Bodlander (1896) hypothesized that gold dissolution in cyanide aqueous solutions occurs in two stages, with perhydrol as an intermediate product, according to the reactions:

$$
\begin{gathered}
2 \mathrm{Au}+4 \mathrm{MeCN}+\mathrm{O}_{2}+2 \mathrm{H}_{2} \mathrm{O} \rightarrow 2 \mathrm{MeAu}(\mathrm{CN})_{2}+2 \mathrm{MeOH}+\mathrm{H}_{2} \mathrm{O}_{2} \\
\mathrm{H}_{2} \mathrm{O}_{2}+2 \mathrm{Au}+4 \mathrm{MeCN} \rightarrow 2 \mathrm{MeAu}(\mathrm{CN})_{2}+2 \mathrm{MeOH} \\
\hline 4 \mathrm{Au}+8 \mathrm{MeCN}+\mathrm{O}_{2}+2 \mathrm{H}_{2} \mathrm{O} \rightarrow 4 \mathrm{MeAu}(\mathrm{CN})_{2}+4 \mathrm{MeOH}
\end{gathered}
$$

d. The Cyanogen Theory: S.B. Christy (1896) came up with the hypothesis that oxygen is necessary for the cyanogen gasformation, through which gold dissolves:

$$
\begin{gathered}
\mathrm{O}_{2}+4 \mathrm{MeCN}+2 \mathrm{H}_{2} \mathrm{O} \rightarrow 2(\mathrm{CN})_{2}+4 \mathrm{MeOH} \\
4 \mathrm{Au}+4 \mathrm{MeCN}+2(\mathrm{CN})_{2} \rightarrow 4 \mathrm{MeAu}(\mathrm{CN})_{2} \\
4 \mathrm{AeCN}+\mathrm{O}_{2}+2 \mathrm{H}_{2} \mathrm{O} \rightarrow 4 \mathrm{MeAu}(\mathrm{CN})_{2}+4 \mathrm{MeOH}
\end{gathered}
$$

e. The Corrosion Theory: B. Boonstra showed in 1943 that gold dissolution in cyanide solutions is similar to the metal corrosion process in which the solution-dissolved oxygen is reduced to perhydrol and hydroxyl ions according to the following mechanism:
Fig.1. Typical areas of gold ligands on the Pourbaix diagram [2] 


$$
\begin{aligned}
\mathrm{O}_{2}+2 \mathrm{H}_{2} \mathrm{O}+2 e & \rightarrow \mathrm{H}_{2} \mathrm{O}_{2}+2 \mathrm{OH}^{-} \\
\mathrm{Au} & \rightarrow \mathrm{Au}^{+}+e \\
\mathrm{Au}^{+}+\mathrm{CN}^{-} & \rightarrow \mathrm{AuCN} \\
\mathrm{AuCN}+\mathrm{CN}^{-} & \rightarrow \mathrm{Au}(\mathrm{CN})_{2}^{-}
\end{aligned}
$$

$\mathrm{Au}+\mathrm{O}_{2}+2 \mathrm{CN}^{-}+2 \mathrm{H}_{2} \mathrm{O}+e \rightarrow \mathrm{Au}(\mathrm{CN})_{2}^{-}+2 \mathrm{OH}^{-}+2 \mathrm{H}_{2} \mathrm{O}_{2}$

f. The Electrochemical Theory: Kudryk and Kellogg (1954) demonstrated that gold dissolution in cyanide solutions is essentially an electrochemical process, a feature also noted in the corrosion theory[10]. As a result, at present the electrochemical nature of the noble metal dissolution in aerated cyanide solutions is unanimously recognized. This implies the simultaneous development of oxidation (anodic reactions) and reduction (cathodic reactions) processes.

Anodic reactions: As it was shown, in cyanide solutions, gold forms predominantly the monovalent complex $\mathrm{Au}(\mathrm{CN})_{2}$

$$
\begin{gathered}
A u \rightarrow A u^{+}+e \\
A u^{+}+2 C N^{-} \rightarrow A u(C N)_{2}^{-} \\
A u+2 C N^{-} \rightarrow A u(C N)_{2}^{-}+e
\end{gathered}
$$

According to Nernst's law, the potential for oxidation of gold with the formation of monovalent gold ions at $25^{\circ} \mathrm{C}$ will depend on their molar concentration according to the relation:

$$
E_{12}=E_{12}^{0}+0.0591 \lg \left[\mathrm{Au}^{+}\right]=-1.69-0.0591 \lg \left[\mathrm{Au}^{+}\right]
$$

The potential of reaction (13) is obtained by varying the reaction free energy, thus:

$$
\begin{aligned}
& \Delta G_{13}=-R T \ln K_{13}+R T \ln \frac{\left[\mathrm{Au} u^{+}\right] \cdot\left[\mathrm{CN}^{-}\right]^{2}}{\left[\mathrm{Au}(\mathrm{CN})_{2}^{-}\right]}=-R T \ln \beta_{2}+R T \ln \frac{\left[\mathrm{Au}(\mathrm{CN})_{2}^{-}\right]}{\left[\mathrm{Au}{ }^{+}\right] \cdot\left[\mathrm{CN}^{-}\right]^{2}} \\
& E_{13}=0.0591 \mathrm{gg} \beta_{2}+0.0591 \mathrm{gg} \frac{\left[\mathrm{Au} u^{+}\right] \cdot\left[\mathrm{CN}^{-}\right]^{2}}{\left[\mathrm{Au}(\mathrm{CN})_{2}^{-}\right]}=2.264+0.05911 \mathrm{~g} \frac{\left[\mathrm{Au} u^{+}\right] \cdot\left[\mathrm{CN}^{-}\right]^{2}}{\left[\mathrm{Au}(\mathrm{CN})_{2}^{-}\right]}
\end{aligned}
$$

where in the square brackets there are the molar concentrations of the species existing at a given moment in the system.

The oxidation potential of gold by reaction (14) is obtained from the sum of the values corresponding to reactions (12) and (13), respectively:

$$
E_{14}=E_{12}+E_{13}=0.574+0.0591 \lg \frac{\left[\mathrm{CN}^{-}\right]^{2}}{\left[\mathrm{Au}(\mathrm{CN})_{2}^{-}\right]}
$$

The positive value of the potential shows that reaction (14) in cyanide solutions occurs in the sense of dissolving metallic gold with the free cyanide anions and forming the auriferous complex. There is a growth in the oxidation potential withthe increase of the free cyanide ions concentration and the decrease of the auriferouscomplexconcentration.

Cathodic Reactions: Along with the electrochemical oxidation reactions, electrochemical reduction reactions occur, the most important of which are the oxygen reduction ones:

$$
\begin{array}{ll}
\mathrm{O}_{2}+2 \mathrm{H}^{+}+2 e \rightarrow \mathrm{H}_{2} \mathrm{O}_{2} ; & E_{15}^{0}=+0.682 \mathrm{~V} \\
\mathrm{O}_{2}+2 \mathrm{H}_{2} \mathrm{O}+4 e \rightarrow 4 \mathrm{OH}^{-} ; & E_{16}^{0}=+0.401 \mathrm{~V}(16)
\end{array}
$$

Reactions (15) and (16) are essentially dependent on the $\mathrm{pH}$ of the solution and the partial oxygen pressure, according to the equations:

$$
\begin{gathered}
E_{15}=0.682-0.0591 \cdot p H+0.0295 \cdot \lg p_{O_{2}} \\
E_{16}=0.401+0.0147 \lg p_{O_{2}}-0.0591 \cdot \lg \left[\mathrm{OH}^{-}\right]
\end{gathered}
$$

Given that under standard conditions $\lg \left[\mathrm{OH}^{-}\right]=p \mathrm{H}-14$, it results:

$$
E_{16}=1.228-0.0591 \mathrm{pH}+0.0147 \mathrm{lg} p_{\mathrm{O}_{2}}
$$

The perhydrol resulting from reaction (15) is a strong oxidizing agent and can be reduced with the formation of hydroxyl anions, according to the reaction

$$
\mathrm{H}_{2} \mathrm{O}_{2}+2 e \rightarrow 2 \mathrm{OH}^{-} ; \quad E_{17}^{0}=+0.88 \mathrm{~V}
$$

However, it was shown [11] that out of the total amount of the perhydrol resulting from reaction (15), only a small part is reduced by reaction (17) with the formation of the hydroxyl, most of it (about 85\%) diffusing into the solution, where it can decompose with the formation of oxygen, which is largely dissolved in water:

$$
2 \mathrm{H}_{2} \mathrm{O}_{2} \rightarrow \mathrm{O}_{2}+2 \mathrm{H}_{2} \mathrm{O}
$$

Even if reaction (15) is thermodynamically possible, the role of perhydrol on the gold dissolution in aqueous cyanide solutions is quite controversial. Some papers $[12,13]$ show that the rate of gold dissolution in solutions containing perhydrol, but in the absence of oxygen, is very low, suggesting an obvious passivation of the gold surface as a result of the formation of anoxide layer which inhibits the leaching process.Other papers $[14,15]$ have shown that small amounts of perhydrol (e.g., $0.015 \mathrm{M} \mathrm{H}_{2} \mathrm{O}_{2}$ in the presence of $0.01 \mathrm{M} \mathrm{NaCN}$ at $\mathrm{pH} 10$ may increase the rate of gold dissolution. However, it is also shown that even with small amounts of perhydrol (e.g. below $0.025 \mathrm{M}$ ) the phenomenon of gold passivation and the decrease of the dissolution rate may occur, especially at $p \mathrm{H} \geq 11$. Generally, it is believed that perhydrol is not an active oxidant for auriferous ores leaching but can play an important role in the oxidation of sulphides. In view of the above, it is unanimously accepted that oxygen is reduced rather by reaction (5) than by reaction (4), even if this requires a higher over potential and is very slow [16].

The Global Gold Dissolution Reaction: Taking into accountthe anodic and cathodic reactions, the electrochemical gold dissolution in oxygenated solutions of alkaline cyanides can be given by a global reaction (Elsner's reaction) obtained from the sum of reactions (14) and (16):

$$
\begin{gathered}
4 \mathrm{Au}+8 \mathrm{CN}^{-} \rightarrow 4 \mathrm{Au}(\mathrm{CN})_{2}^{-}+4 e \\
\frac{\mathrm{O}_{2}+2 \mathrm{H}_{2} \mathrm{O}+4 e \rightarrow 4 \mathrm{OH}^{-}}{4 \mathrm{Au}+8 \mathrm{CN}^{-}+\mathrm{O}_{2}+2 \mathrm{H}_{2} \mathrm{O} \rightarrow 4 \mathrm{Au}\left(\mathrm{CN}_{2}^{-}+4 \mathrm{OH}^{-}\right.} \\
E_{19}=1.802+0.0591 \mathrm{lg} \frac{\left[\mathrm{CN}^{-}\right]^{2}}{\left[\mathrm{Au}(\mathrm{CN})_{2}^{-}\right]}-0.0591 \mathrm{pH}+0.0147 \mathrm{lg} \mathrm{PO}_{2}
\end{gathered}
$$

From the expression of the electrode potential of the global gold dissolution reaction in aerated solutionsof alkaline cyanides, itresults that this is favored by increasing the cyanide ions concentration, lowering the auriferous complex concentration in the solution, lowering the $\mathrm{pH}$, 
and increasing the oxygen concentration in the aqueous solution. However, it has to be taken into account that the $\mathrm{pH}$ in the cyanide leaching processes should be maintained at values higher than 10 to prevent the hydrolysis of the cyanide ions with the formation and release of the hydrogen cyanide.

\section{Conclusions}

The thermodynamic analysis on the gold dissolution in various lixiviants highlighted the following:

- the thermodynamic stability of the gold complexes with different lixiviants depends on the nature of the donor ligand atoms:more electronegative donors form predominantly complexes with the trivalent gold, such as halogens, and lower electronegativity donors form predominantly complexes with the monovalent gold, such as cyanides, thiosulphates, thiourea and thiocyanates;

- depending on the nature of the lixiviant, gold dissolution becomes thermodynamically possible at an acceptable rate only in the presence of oxidants, and in other situations, in addition to oxidants, other specific reagents (catalysts and / or stabilizers) are also required.

\section{References}

1.*** Directiva 2006/21/CE a Parlamentului European si a Consiliului privind gestioarea deseurilor din industriile extractive, Jurnalul Oficial al Uniunii Europene, Cap.15/vol.16/11.04.2006, p.3-22,2006;

2.M. ARMITAGE, Technical report on the Rosia Montanã gold and silver project, SRK Consulting (UK) Limited, October 2012;

3.ALEXANDER, R., JURAS, S., MILLER, R., KALANCHEY, R., Technical Report for the Certej Project, Romania, http://s2.q4cdn.com/536453762/ files/doc_downloads/Reports/Technical_Report-Certej (Feb_2014).pdf; 4.AYLMORE, M.G., Alternative lixiviants to cyanide for leaching gold ores, Advances in gold ore processing, pp. 501-539, Edited by M.D. Adams, Elsevier, Amsterdam, 2005;
5.ZHANG, S., Oxidation of refractory gold concentrates and simultaneous dissolution of gold in aerated alkaline solution, Thesis, Murdoch University Weastern Australia, 2004;

6.NICOL, M.J., FLEMING, C.A., PAUL, R.L., The Chemistry of the Extraction of Gold, Chap. XV, The Extractive Metallurgy of Gold in South Africa, vol.2, Edited by G.G. Stanley, The South African Institute of Mining and Metallurgy, Monograph Series M7, J ohannesburg, 1987; 7.YANNOPOULOS, J.C., The Extractive Metallurgy of Gold, Van Nostrand Reihold, New York, 1991;

8.HABASHI, F., One hundred years of cyanidation, C.I.M. Bulletin, vol.80 (905), pp 108-114, 1987;

9.CORNEJ O, L.M., SPOTTISWOOD, D.J., Fundamental aspects of the gold cyanidation process: a review, Mineral \& Energy Resources, Colorado School of Mines, 1984;

10.KUDRYK, V., Kellogg, H.H., Mechanism and rate-controlling factors in the dissolution of gold in cyanide solution. J ournal of Metals, vol.6, No.5, pp 541- 548, 1954;

11.HUANG, H-H., The Eh-pH Diagram and its Advances, Metals, vol.6, No 23, 2016;

12.ZURILLA, R.W., SEN, R.K., YEAGER, E., The kinetics of oxygen reduction reaction on gold in alkaline solution, Journal of Electrochemical Society, vol.125, pp. 1103-1109, 1978;

13.KIRK, D.W., FOULKES, F.R., GRAYDON, W.F., A sudy of anodic dissolution of gold in aqueous alkaline cyanide, Journal of Electrochemical Society, vol.125, pp. 1436-1443, 1978;

14.GUZMAN, L.M., SEGARRA, J.M., CHIMENOS, M.A., FERNANDEZ, M.A., ESPIELL, F., Gold cyanidation using hydrogen peroxide, Hydrometallurgy, vol.52, pp. 21-35, 1999;

15. BALL, S.P., MONHEMIUS, A.J., WYBORN, P. ., The use of inorganic peroxides as accelerators for gold heap leaching, Proceedings of Precious Metals'89, pp. 149-164, Edited by M.C. J ha ans S.D. Hill, Warrendale, PA, TMS, 1989;

16.MARSDEN, J.O, IAIN HOUSE, C., The Chemistry of Gold Extraction, Second Edition, SME, Englewood, Colorado, 2006

$\overline{\text { Manuscript received: } 27.07 .2019}$ 